\title{
Transgenic barley plants overexpressing a 13-lipoxygenase to modify oxylipin signature
}

\author{
Vijendra K. Sharma ${ }^{\text {a }}$, Tamas Monostori ${ }^{\text {b,1 }}$, Cornelia Göbel ${ }^{\mathrm{c}}$, Robert Hänsch ${ }^{\mathrm{a}}$, \\ Florian Bittner ${ }^{\mathrm{a}}$, Claus Wasternack ${ }^{\mathrm{b}}$, Ivo Feussner ${ }^{\mathrm{c}}$, Ralf R. Mendel ${ }^{\mathrm{a}}$, \\ Bettina Hause ${ }^{b}$, Jutta Schulze ${ }^{a, *}$ \\ a Department of Plant Biology, Technical University of Braunschweig, Humboldtstr. 1, D-38106 Braunschweig, Germany \\ ${ }^{\mathrm{b}}$ Leibniz Institute of Plant Biochemistry, P.O. Box 110432, D-06018 Halle/Saale, Germany \\ ${ }^{\mathrm{c}}$ Albrecht von Haller Institute for Plant Sciences, Department of Plant Biochemistry, Georg-August-University, \\ Justus-von-Liebig Weg 11, D-370977 Göttingen, Germany
}

Received 22 September 2005; received in revised form 8 November 2005

Available online 27 December 2005

\begin{abstract}
Three chimeric gene constructs were designed comprising the full length cDNA of a lipoxygenase (LOX) from barley (LOX2:Hv:1) including its chloroplast targeting sequence (cTP) under control of either (1) CaMV35S- or (2) polyubiquitin-1-promoter, whereas the third plasmid contains 35S promoter and the cDNA without cTP. Transgenic barley plants overexpressing $L O X 2: H v: 1$ were generated by biolistics of scutella from immature embryos. Transformation frequency for $35 \mathrm{~S}:: L O X$ with or without cTP was in a range known for barley particle bombardment, whereas for Ubi::cTP-LOX no transgenic plants were detected. In general, a high number of green plantlets selected on bialaphos became yellow and finally died either in vitro or after potting. All transgenic plants obtained were phenotypically indistinguishable from wild type plants and all of them set seeds. The corresponding protein (LOX-100) in transgenic T0 and T1 plants accumulated constitutively to similar levels as in the jasmonic acid methyl ester (JAME)-treated wild type plants. Moreover, LOX100 was clearly detectable immunocytochemically within the chloroplasts of untreated T0 plants containing the LOX-100-cDNA with the chloroplast target sequence. In contrast, an exclusive localization of LOX-100 in the cytoplasm was detectable when the target sequence was removed. In comparison to sorbitol-treated wild type leaves, analysis of oxylipin profiles in T2 progenies showed higher levels of jasmonic acid (JA) for those lines that displayed elevated levels of LOX-100 in the chloroplasts and for those lines that harboured LOX-100 in the cytoplasm, respectively. The studies demonstrate for the first time the constitutive overexpression of a cDNA coding for a 13-LOX in a monocotyledonous species and indicate a link between the occurrence of LOX-100 and senescence.
\end{abstract}

(C) 2005 Elsevier Ltd. All rights reserved.

Keywords: Hordeum vulgare L.; Poaceae; Lipoxygenase; Oxylipin levels; Transgenic barley plants

Abbreviations: cTP, chloroplast targeting peptide; 35S, cauliflower mosaic virus 35S promoter; 13-HPOT, (13S,9Z,11E,15Z)-13-hydroperoxy-9,11,15-octadeca-trienoic acid; JA, jasmonic acid; JAME, jasmonic acid methyl ester; $\alpha$-LeA, $\alpha$-linolenic acid; LOX, lipoxygenase; MS, Murashige and Skoog; OPDA, 12-oxo-phytodienoic acid; PAT, phosphinothricin $N$-acetyltransferase; PPT, phosphinothricin; Ubi-1, polyubiquitin-1 promoter.

* Corresponding author. Tel.: +49 531391 5869; fax: + 495313918128.

E-mail address: Jutta.Schulze@tu-bs.de (J. Schulze).

${ }^{1}$ Present address: Department of Plant Production and Horticulture, College of Agriculture, University of Szeged, Andrássy street 15, H-6800 Hódmezövásárhely, Hungary.

\section{Introduction}

In the last decade numerous data accumulated that oxygenated fatty acids and metabolites derived therefrom, collectively called oxylipins, play an important role in the regulation of environmentally induced and developmental-specific processes during plant life (Weber, 2002). Most of these oxylipins are generated via the lipoxygenase pathway. 
Lipoxygenases (LOXs, linoleate:oxygen oxidoreductases, EC 1.13.11.12), ubiquitous in higher eukaryotes, are non-heme iron containing dioxygenases which catalyse the stereospecific addition of molecular oxygen to polyunsaturated fatty acids either at carbon atom C-9 or at carbon atom $\mathrm{C}-13$ of $\mathrm{C}-18$ fatty acids leading to the formation of unsaturated fatty acid hydroperoxides. Based on this positional specificity LOX isoenzymes are grouped into linoleate 9-LOX and 13-LOX types. An additional classification of plant LOXs is based on comparison of their primary structure. Enzymes with a high sequence similarity $(>75 \%)$ are termed type 1-LOXs while those enzymes showing only a moderate overall sequence similarity $(\sim 35 \%)$ but carrying a putative chloroplast transit peptide have been classified as type 2-LOXs (Rosahl, 1996).

In plants, $\alpha$-linolenic acid ( $\alpha$-LeA) or linoleic acid as the main substrates are converted via LOX into hydroperoxy polyunsaturated fatty acids, which are the substrates for at least seven different pathways (Feussner and Wasternack, 2002). Most of these LOX-generated substances from the different reactions are involved in developmental processes and defence responses as supported by the following data: (1) Jasmonic acid (JA), a plant hormone derived from the LOX pathway, acts as an important signalling compound on pollen development, root growth and defence responses to herbivore and pathogen attack as demonstrated by JAbiosynthesis and JA-insensitive mutants as well as transgenic approaches (Wasternack and Hause, 2002; Howe, 2004; Pozo et al., 2004; Devoto and Turner, 2005), (2) $\mathrm{C}_{6}$ volatiles are able to induce defence related genes (Paré and Tumlinson, 1997; Bate and Rothstein, 1998; Koch et al., 1999), (3) aldehydes derived by the action of a hydroperoxide lyase revealed antimicrobial activity (Croft et al., 1993), (4) divinyl ethers such as colnelenic acid accumulate after pathogen attack and exhibit antimicrobial activity (Weber et al., 1999), and (5) transgenic plants with overexpression of a LOX gene or by antisense expression of LOX sequences are affected in defence responses (Bell et al., 1995; Rancé et al., 1998; Mène-Saffrané et al., 2003). Based on these effects LOXs are thought to be a key regulator of a complex signalling network.

In barley leaves, JA treatment leads to the formation of JA-induced proteins of different molecular masses (Lehmann et al., 1995). Among them are three LOX forms with the molecular masses of 92,98 and $100 \mathrm{kDa}$ (LOX-92, LOX-98, LOX-100). They were identified as 13-LOXs located within the chloroplasts (Feussner et al., 1995). The cDNA of the most abundant form LOX-100 was isolated and designated as LOX2:Hv:1 (Vörös et al., 1998). The protein accumulates in JA-treated primary leaves, and its gene expression is induced by salicylate treatment but not by pathogens (Hause et al., 1999). In addition to $L O X 2: H v: 1$, two full length cDNAs (LOX2:Hv:2, $L O X 2: H v: 3$ ) were isolated from primary leaves of barley seedlings. Both of them encode 13-LOXs, and immunogold labelling revealed preferential localization of the proteins in the stroma of plastids (Bachmann et al., 2002). Metabolic profiling revealed that 13 -LOX-derived products are specifically directed into the reductase branch upon salicylate treatment (Weichert et al., 1999), whereas JAME treatment caused a selective induction of LOX and hydroperoxide lyase activity resulting in the endogenous occurrence of volatile leaf aldehydes (Kohlmann et al., 1999). Further analyses revealed that the three 13-LOXs are differentially expressed during treatment with jasmonate, salicylate, glucose or sorbitol (Bachmann et al., 2002) suggesting varying activity of the three enzymes under different stress conditions.

As a first step to study the physiological function of $L O X 2: H v: 1$, we have used a transgenic approach for Hordeum vulgare L. cv. 'Salome'. We transformed the cDNA encoding LOX-100 with and without the chloroplast targeting signal in a homologous approach via biolistics using scutella from immature embryos. Based on that, activity and quantity of the enzyme should be modified in the cytoplasm and the chloroplasts. Enzymatic activity of LOX-100 in different compartments should lead to different profiles of oxylipins due to the localization of the other enzymes of the LOX pathway. Furthermore, a possible influence of LOX-100-derived products on plant growth and development was expected. This is the first report for monocots on stable overexpression of a 13-LOX either in chloroplasts or cytoplasm.

\section{Results}

\subsection{Generation of transgenic barley plants}

The designed constructs p35S::cTP-LOXUbi::bar (L1), pUbi::cTP-LOX35S::pat (L2) and p35S::LOXUbi::bar (L3) (Fig. 1) were found to be functional as revealed by transient assays using direct gene transfer into mesophyll protoplasts from in vitro grown seedlings of cv. Salome. For the selectable bar or pat gene, a strong activity could be detected in the phosphinothricin $N$-acetyltransferase (PAT)-assay two days after transformation independently from the promoter used, whereas immunoblot analysis revealed a weak accumulation of LOX-100 in transient assays (data not shown).

Immature scutella of the spring type cv. Salome used as starting explants were transformed through particle bombardment with the three different LOX constructs and selected on bialaphos-containing medium. Putative transgenic plants were regenerated via somatic embryogenesis from the bombarded scutella with all three constructs, and subsequently selected (Table 1). The regeneration frequency is calculated as number of plants regenerated per scutella used for selection. For the constructs L1 and L3 comprising $\mathrm{LOX} 2: \mathrm{Hv}: 1$ under control of the $35 \mathrm{~S}$ promoter, a regeneration frequency of $4.2 \%$ and $5.3 \%$, respectively, was found. In contrast, plasmid L2 containing the Ubi-1 promoter in front of the LOX-100-encoding cDNA yielded only one tenth of the regeneration frequency observed for L1 and L3. A high number of green and well-rooted 

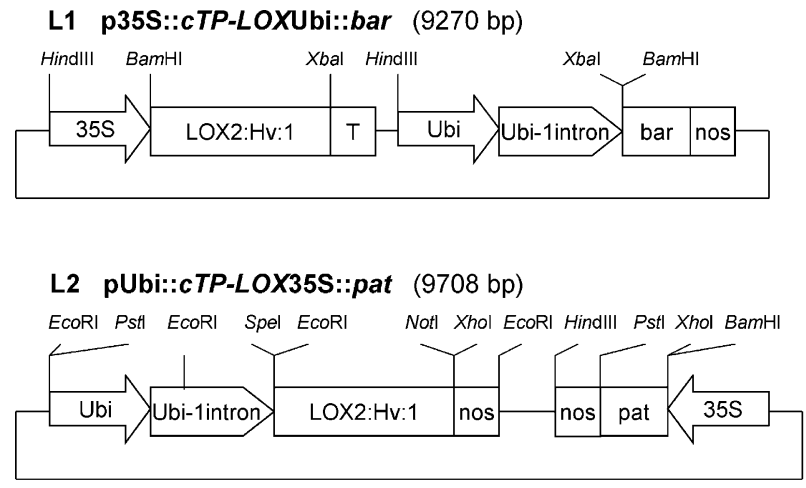

L3 p35S::LOXUbi::bar (9137 bp)

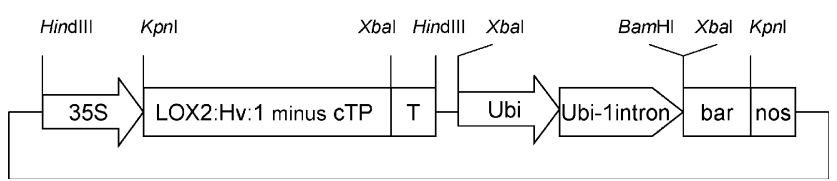

Fig. 1. Schematic representation of the three plasmids containing the LOX-100-cDNA used for barley transformation. Molecular sizes are given in bp and sites of restriction endonucleases are indicated. T represents the poly A signal of CaMV $35 \mathrm{~S}$ as terminator.

plantlets that developed on bialaphos, turned yellow and died either during further development in vitro or after transfer to soil. The percentage of dead plants determined was almost equal for L1 and L2 comprising the cDNA with the chloroplast target sequence (Table 1). In comparison, for $\mathrm{L} 3$ containing $35 \mathrm{~S}:: L O X$ without target sequence, the percentage of dead plants was slightly lower. For all three constructs a negligible number of albinotic plants regenerated (Table 1).

\subsection{Analysis of T0 plants for the selectable gene}

First analyses of the activity of the selectable gene, carried out with randomly chosen bialaphos-resistant callus lines and first regenerants, showed strong signals in the PAT-assay (data not shown). For further screening on
PAT activity of the T0 plants, the resistance to phosphinothricin (PPT)-treatment of leaves was tested (Table 1) using the leaf painting assay as described under Section 4. Two weeks later leaves with complete yellowish or brown coloration indicative of substantial necrosis were susceptible whereas leaves with little or no damage showed resistance indicating the functional activity of PAT. The selected plants grew well in soil, and L1 and L3 plants revealed fifty percent PPT-resistance.

All bialaphos-selected plants were screened for the activity of the marker gene and for the presence of marker sequences by PCR analysis (data not shown). Putative transgenic plants which did not show PCR-products for the bar gene (L1 and L3; $452 \mathrm{bp}$ ) or the pat gene (L2; $429 \mathrm{bp}$ ) were discarded. For L1 and L3 plants the frequency was between $60 \%$ and $48 \%$, respectively, revealing a high percentage of escapes, whereas no positive L2 plant was found. These results of PCR analysis were consistent with that observed with the PPT leaf painting assay. The transformation frequency for the selectable gene, calculated as number of plants regenerated per scutella used for selection, is $0.64 \%$ for $\mathrm{L} 1$ and $0.95 \%$ for L3. Furthermore, the plants originate from different bombardment experiments thus representing independent transformation events.

\subsection{Analysis of T0 plants for the co-transformed gene}

Plants, PCR-positive for the marker, were analysed with respect to $L O X 2: H v: 1$ integration using two primer sets. The endogenous LOX2:Hv:1 gene could be distinguished from the transgene due to the presence of two introns (Fig. 2A). The transgene status was further verified with a second primer pair for a $1600 \mathrm{bp}$ fragment of the $35 \mathrm{~S}$ promoter + HvLOX-100int $\mathrm{b}$ as given under Section 4 (Fig. 2B). Sequencing of the respective PCR-fragment confirmed the identity of the $35 \mathrm{~S}$ promoter and the $L O X$ segment. The co-transformation efficiencies, given as number of PCR $L O X$-positive plants calculated on the basis of bar- or pat-positive tested plants, were $26 \%$ (L1) and $31 \%$

Table 1

Status of regeneration and survival of T0 plants after transformation with cDNA from LOX2:Hv:1 used for biochemical analysis

\begin{tabular}{|c|c|c|c|c|c|c|c|c|c|c|}
\hline \multirow{3}{*}{ Construct } & \multicolumn{2}{|l|}{ Number of } & \multicolumn{8}{|c|}{ Number of plants } \\
\hline & \multirow{2}{*}{$\begin{array}{l}\text { Independent } \\
\text { transformation } \\
\text { experiments }\end{array}$} & \multirow{2}{*}{$\begin{array}{l}\text { Scutella } \\
\text { used for } \\
\text { selection }\end{array}$} & \multicolumn{2}{|c|}{$\begin{array}{l}\text { Regenerated } \\
\text { on bialaphos }\end{array}$} & \multicolumn{4}{|c|}{ Died after selection } & \multirow[t]{2}{*}{$\begin{array}{l}\text { Available for } \\
\text { analysis }\end{array}$} & \multirow[t]{2}{*}{$\begin{array}{l}\text { PPT treatment } \\
\text { tested/positive }\end{array}$} \\
\hline & & & Total $^{\mathrm{a}}$ & $\%{ }^{\mathrm{b}}$ & In vitro $^{c}$ & In soil ${ }^{\mathrm{d}}$ & Total & $\%$ & & \\
\hline \multicolumn{11}{|l|}{$\overline{\mathrm{L} 1}$} \\
\hline $\begin{array}{l}35 \mathrm{~S}:: c T P-L O X \\
\mathrm{~L} 2\end{array}$ & 12 & 3591 & $150(7)$ & 4.2 & 83 & 21 & 104 & 69 & 39 & $30 / 15$ \\
\hline $\begin{array}{l}\text { Ubi::cTP-LOX } \\
\text { L3 }\end{array}$ & 20 & 5982 & $27(2)$ & 0.4 & 18 & 1 & 19 & 70 & 6 & $3 / 1$ \\
\hline $35 \mathrm{~S}:: L O X$ & 16 & 4732 & $253(9)$ & 5.3 & 109 & 33 & 142 & 56 & 102 & $56 / 28$ \\
\hline
\end{tabular}

\footnotetext{
${ }^{a}$ The regenerated albinotic plants which included in the total number are given in parentheses.

${ }^{b}$ Regeneration frequency is calculated as number of plants regenerated per immature embryo used for selection.

${ }^{c}$ Plants with well developed root and shoot system on $3 \mathrm{mg} / \mathrm{l}$ bialaphos.

${ }^{\mathrm{d}}$ Well developed plantlets died in soil 6-8 weeks after potting.

e $0.25 \%$ (w/v) PPT (glufosinate ammonium).
} 

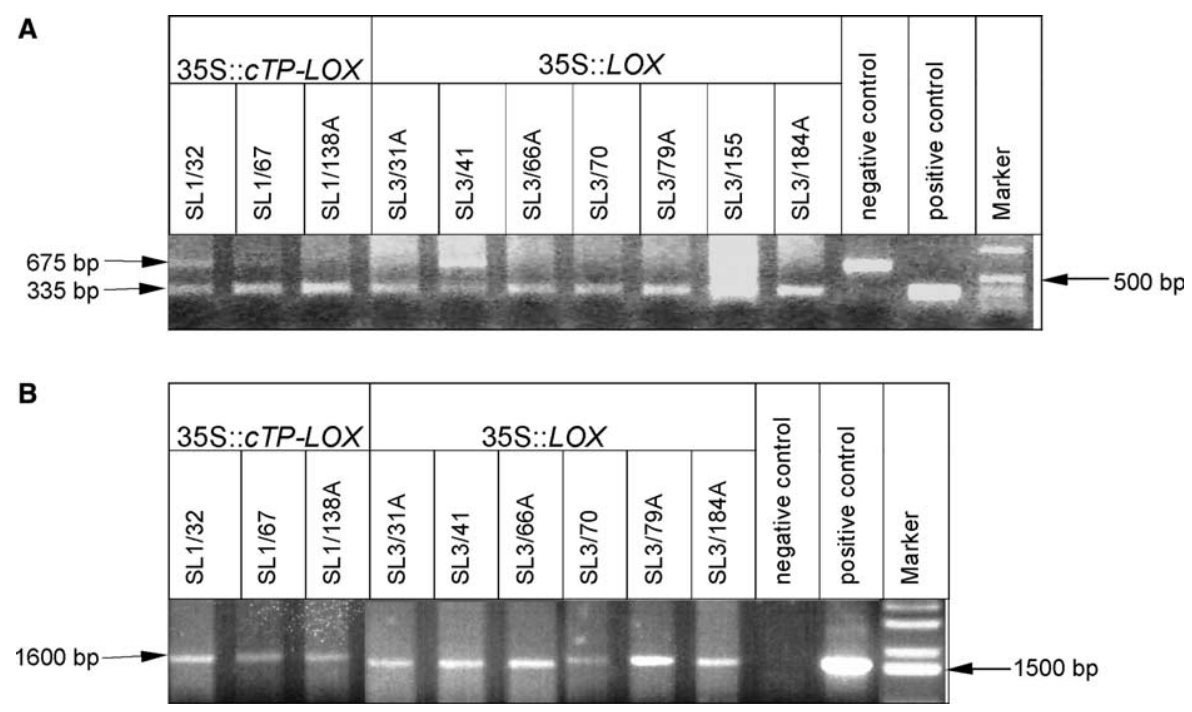

Fig. 2. PCR analysis of genomic DNA extracted from wild type and transgenic barley plants performed as described under Section 4. LOX-PCR products of 675 and $335 \mathrm{bp}$ were amplified using the primers HvLOX-100int a and HvLOX-100int b (A). LOX PCR product of $1600 \mathrm{bp}$ was amplified using the primers 35S promoter region 351-368 and HvLOX-100int b (B). Negative control: genomic DNA isolated from non-transformed barley leaves. Positive control: plasmid DNA. Arrows indicate the position of the expected fragments.

(L3) (Table 2). Nevertheless, total transformation efficiencies for the gene of interest were determined as $0.17 \%$ for $\mathrm{L} 1$ and $0.29 \%$ for L3, while no plants could be detected for L2. All plants proved positive for $35 \mathrm{~S}:: c T P-L O X$ as well as $35 \mathrm{~S}:: L O X$ were morphologically indistinguishable from wild type plants and set seeds after self pollination.

\subsection{Immuno analysis of $T 0$ plants}

Accumulation of LOX-100 in transgenic barley plants was examined by immunoblot analysis with leaves from well-developed greenhouse plants. Significant level of LOX-100 was detected in all PCR-positive lines (Fig. 3). In these unstressed T0 plants, LOX protein of $100 \mathrm{kDa}$ accumulated to similar amounts as in wild type plants treated with JAME for $36 \mathrm{~h}$ (Fig. 3A). In wild type leaf segments treated with water, only a very weak or undetectable level of LOX-100 protein was observed. Immunoblot analyses of putative transgenic plants grown in vitro but turned yellow revealed weak protein of $100 \mathrm{kDa}$ molecular mass, instead a significant amount of a $98 \mathrm{kDa}$ protein and lower amounts of a $92 \mathrm{kDa}$ protein appeared (Fig. 3B).

Immunofluorescence analyses were performed using LOX antibodies in order to determine the location of the
LOX-100 encoded by the LOX2:Hv:1 and expressed with and without chloroplast target sequence. In cross sections of untreated leaves from wild type, no specific label was detectable, whereas chloroplasts exhibited only yellowish autofluorescence (Fig. 4A). In contrast, in untreated T0 plants carrying $35 \mathrm{~S}:: c T P-L O X$ a clear label within the chloroplasts of all mesophyll cells was visible (Figs. 4B-D). The tested plants (SL1/63 and SL2/9) showing high levels of LOX-100 protein in the immunoblot analysis belonged to the green and well-rooted plants developed on bialaphos but turned yellow and died during further development in vitro. The four randomly chosen plants carrying $35 \mathrm{~S}:: L O X$ displayed an exclusive location of LOX-100 in the cytoplasm (Figs. 4E-G) occurring as a thin layer around the autofluorescent chloroplasts.

\subsection{Analysis of $T 1$ and $T 2$ plants}

T1 plants were generated via the bialaphos-resistance test using dissected mature embryos from seeds of $\mathrm{T} 0$ plants carrying $35 \mathrm{~S}:: c T P-L O X$ as well as $35 \mathrm{~S}:: L O X$. Embryos were scored for survival ratio with respect to segregation of the bialaphos-resistant phenotype. A germination frequency of about $70 \%$ was determined except for

Table 2

Results of PCR analyses using different primer pairs for molecular analysis of T0 plants

\begin{tabular}{lllll}
\hline Construct & Number of plants & & \\
\cline { 2 - 5 } & bar or pat tested/pos. & LOX $^{\mathrm{a}}$ tested/pos. & LOX $^{\mathrm{b}}$ tested/pos. & Ratio $^{\mathrm{c}}$ bar $^{+} /$LOX $^{+}$ \\
\hline L1 35S::cTP-LOXUbi::bar & $38 / 23$ & $38 / 6$ & $6 / 6$ & $23 / 6(26 \%)$ \\
L2 Ubi::cTP-LOX35S::pat & $6 / 0$ & $6 / 0$ & $0 / 0$ & $0 / 0$ \\
L3 35S::LOXUbi::bar & $94 / 45$ & $94 / 14$ & $14 / 13$ & $45 / 14(31 \%)$ \\
\hline
\end{tabular}

a Primer for a 335-bp LOX fragment.

b All PCR $L O X$-positive plants were tested with a second primer pair for a 1600 bp fragment 35S promoter $+L O X$.

${ }^{\mathrm{c}}$ In parentheses co-transformation efficiency is given. 

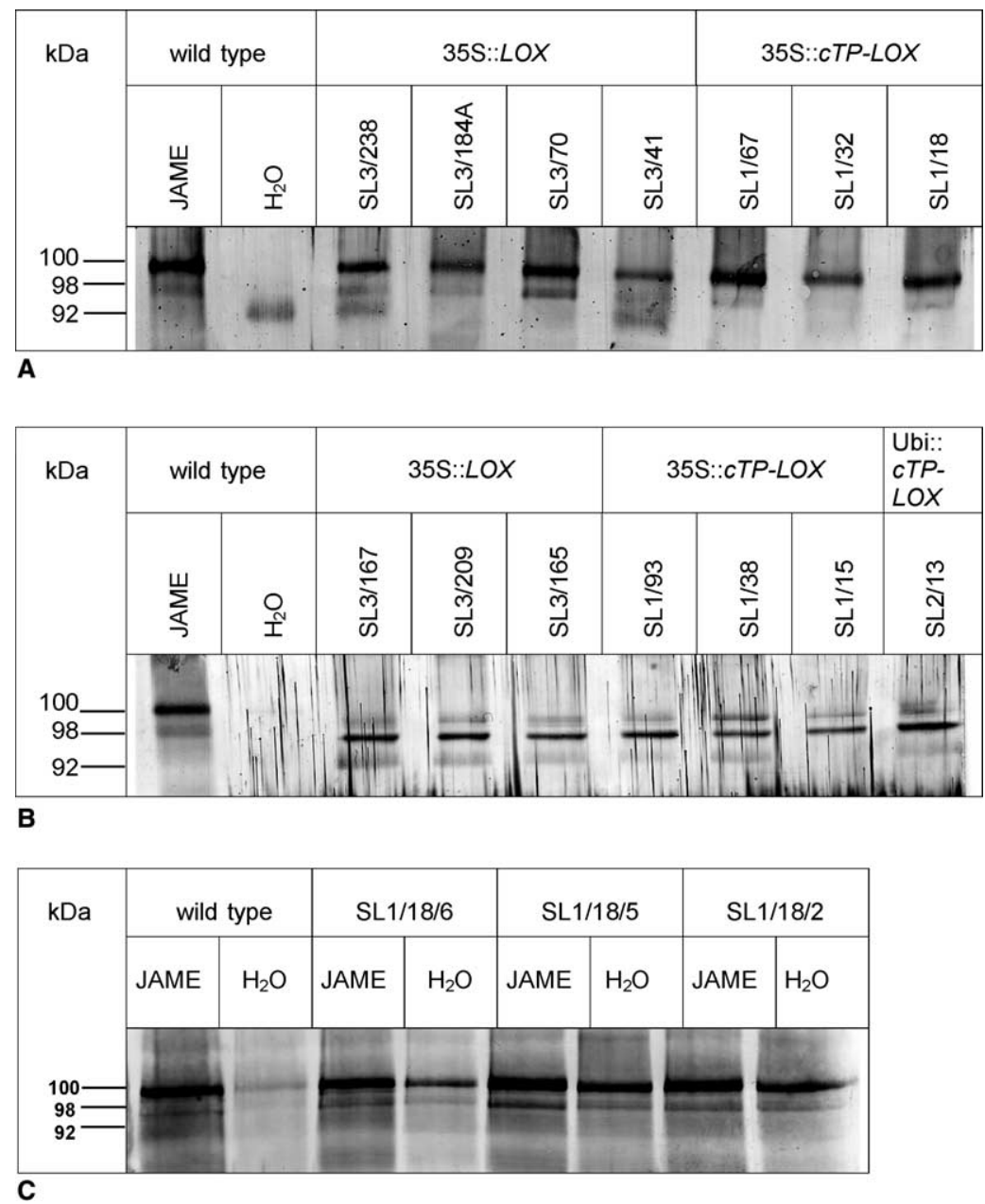

Fig. 3. Immunoblot analysis of LOX-100 protein accumulation in transgenic barley plants. Ten $\mu$ g total protein were separated on SDS/PAGE and transferred onto nitrocellulose membranes. LOX protein was detected by specific reaction with antiserum against LOX from cucumber and visualized by peroxidase-conjugated secondary antibodies. Leaf segments from well-developed and well-tillered greenhouse grown T0 plants (A), leaf material from in vitro plants turned yellow after successful regeneration as green plants (B), and leaf segments from well-developed and well-tillered greenhouse-grown $\mathrm{T} 1$ plants untreated $\left(\mathrm{H}_{2} \mathrm{O}\right)$ and treated by flotation on $45 \mu \mathrm{M}$ JAME for $36 \mathrm{~h}(\mathrm{C})$. In all cases leaf segments of a corresponding wild type untreated $\left(\mathrm{H}_{2} \mathrm{O}\right)$ and $45 \mu \mathrm{M}$ JAME-treated were used.

SL3/41. A relatively low number of the successfully germinated embryos continued to grow on $5 \mathrm{mg} / 1$ bialaphos (Table 3). These plantlets were tested for the presence of the nonselectable transgene using PCR (data not shown) and were transferred to soil. The transgene was stably transmitted to the subsequent generation in most of the lines evaluated (Table 3). The co-expression ratio was about $30 \%$. Furthermore, leaves showed a remarkable accumulation of LOX-100 as tested by immunoblot analyses (Fig. 3C). Independent offsprings from T0 plants carrying 35S::cTP-LOX (Fig. 3C) as well as 35S::LOX (not shown) exhibited with and without treatment with JAME similar LOX levels as JAME-treated wild type leaves.

Seeds of five transgenic lines showing a modified spectrum of LOX-metabolites in HPLC analyses were germinated in soil without any selection pressure to get normal primary leaves for stress treatment as mentioned in Section 4. The T2 generation was screened by PCR with both LOX-specific primer pairs. From 121 offsprings of L1 and 156 offsprings of L3 six and 11 plants, respectively, were positive.

\subsection{Analysis of LOX-metabolites}

Leaves from 35S::cTP-LOX and 35S::LOX transgenic $\mathrm{T} 0$ plants grown in the greenhouse were analysed concerning free and esterified fatty acids as well as free LOXderived hydroxy fatty acids. No changes were found in the fatty acid profiles of transgenic T0 compared to wild type plants. Moreover, wild type plants showed a high degree of variation in their content of free fatty acids as well as free hydroxy fatty acids, despite the plants were grown under the same conditions (data not shown).

Since LOX activity obviously depends on its substrate, analyses of $\mathrm{T} 1$ plants were performed after floating of leaves from 6-week-old soil-grown plants on $45 \mu \mathrm{M}$ JAME for $36 \mathrm{~h}$. Further, in previous experiments it was shown that JAME-treatment lead to increased formation of 13 - 

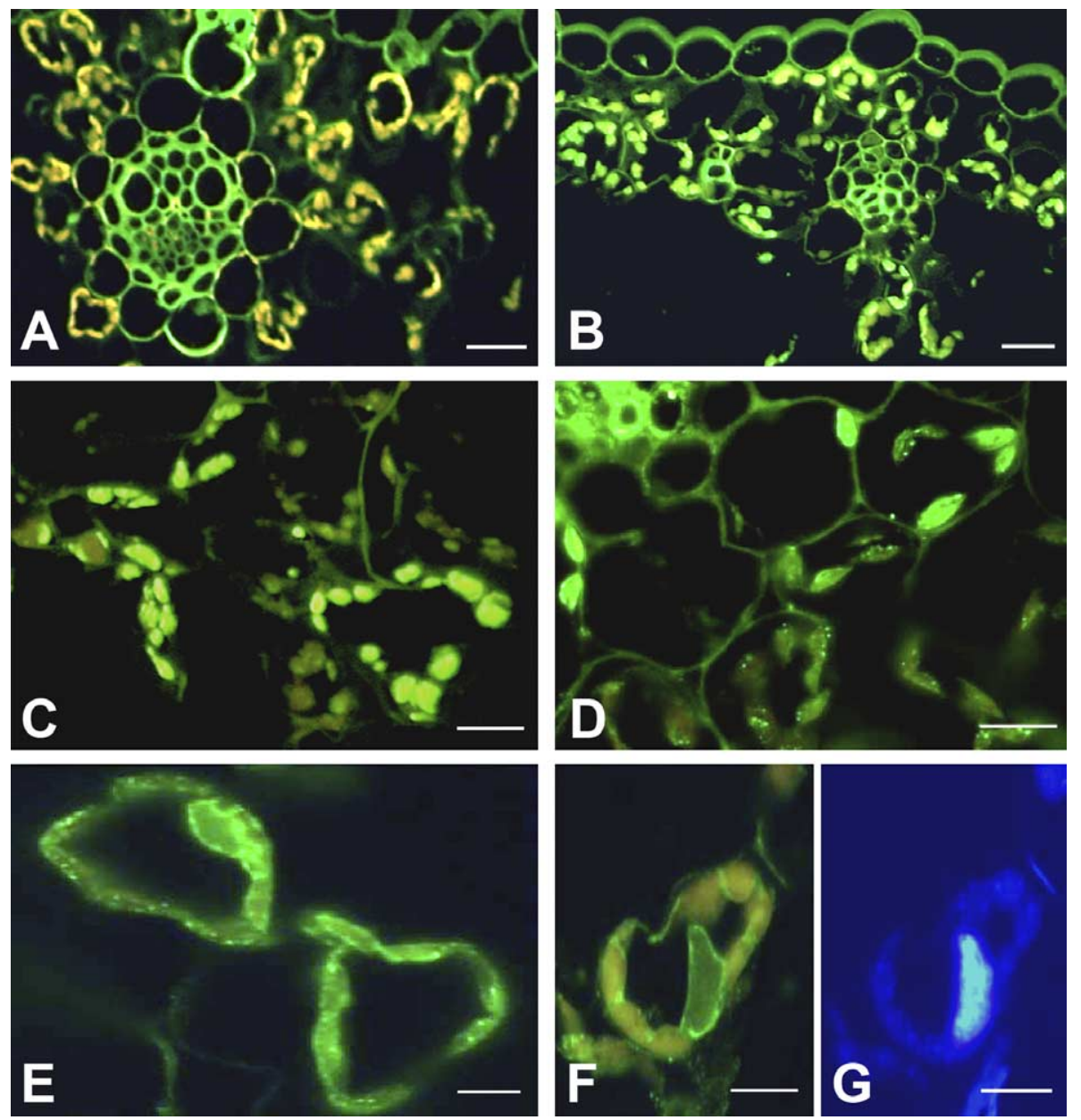

Fig. 4. Survey of the localization of LOX-100 protein in cross sections of untreated leaves of wild type plants (A) and transgenic T0 plants carrying 35S::cTP-LOX (B, C), Ubi::cTP-LOX (D) and 35S::LOX (E-G). Leaves were harvested from in vitro grown plantlets and were all in the same developmental stage. Note the autofluorescence of chloroplasts in A, whereas SL1/18 (B), SL1/63 (C) and SL2/9 (D) exhibit strong green fluorescence in chloroplasts due to the immuno decoration of LOX. In contrast, in SL3/5 (E) and SL3/14 (F) the label is restricted to the cytoplasm surrounding the chloroplasts. $\mathrm{G}$ shows the concomitant DAPI staining of $\mathrm{F}$ to visualize the nucleus and the DNA-containing organelles. Bars represent $10 \mu \mathrm{m}$.

LOX-derived 13-HPOT (Bachmann et al., 2002). For comparison, leaf segments from wild type plants treated with water as well as $45 \mu \mathrm{M}$ JAME for $36 \mathrm{~h}$ were used. Interestingly, the amount of 13-HPOT was reduced in 16 out of 17 lines that accumulate LOX-100 in the cytoplasm. In only two out of seven lines accumulating LOX-100 in the chloroplasts, the amount of 13-HPOT was reduced compared to the wild type (Fig. 5A). For the aldehydes no changes could be found (data not shown).

On the basis of these data, one T1 line for L1 (SL1/18/6) and three lines for L3 (SL3/31a/23; SL3/31a/25; SL3/238/ 21) were selected from which $20-100$ progeny (T2) seedlings were germinated each. At least in the case of SL1/ $18 / 6$, this line exhibited high LOX-100 protein levels (Fig. 3C). Primary leaf segments were treated with $1 \mathrm{M}$ sorbitol and analysed for their levels of OPDA and JA (Figs. 5B and $\mathrm{C}$ ), since treatment was shown to lead to an increase in endogenous JA (Lehmann et al., 1995). Except one plant, the amount of OPDA was unchanged in all transgenic lines in comparison to the wild type (Fig. 5B). In contrast, four plants overexpressing plastid-directed
$L O X-100$ exhibited elevated levels of JA. Five out of 11 plants that overexpress cytoplasmic-directed $L O X-100$ showed reduced levels of JA, while three showed elevated levels and three remained unchanged in comparison to the wild type (Fig. 5C).

\section{Discussion}

Here we describe for the first time the constitutive overexpression of a LOX coding for a 13-LOX ( $L O X 2: H v: 1)$ in transgenic barley. To this end, there are only a few studies, all in dicots, on genetic manipulation of LOXs. In order to analyse the probable involvement of a type 2-LOX in JA synthesis, one of the six $L O X S$ of Arabidopsis thaliana the $L O X 2$ was overexpressed in A. thaliana. A reduced LOX accumulation due to co-suppression without any influence on growth and development was found in these LOX2transgenic plants. However, wound-induced accumulation of JA which was observed in wild type plants did not occur (Bell et al., 1995). For potato, the involvement of a 
Table 3

Analysis of $\mathrm{T} 1$ progeny of $L O X$-positive T0 plants: T1 progeny selected from germination-test ( $\mathrm{MS}+5 \mathrm{mg} / \mathrm{l}$ bialaphos) using mature embryos excised from $\mathrm{T} 0$ seeds

\begin{tabular}{|c|c|c|c|c|}
\hline \multirow[t]{2}{*}{ T0 plant } & \multicolumn{3}{|c|}{ Number of embryos } & \multirow{2}{*}{$\begin{array}{l}\text { Number of } \mathrm{T} 1 \\
\text { progeny selected }^{\mathrm{b}} / \\
\text { positive in } \\
L O X \mathrm{PCR}^{\mathrm{c}}\end{array}$} \\
\hline & $\begin{array}{l}\text { Used } \\
\text { total }\end{array}$ & $\begin{array}{l}\text { Germinated }^{\mathrm{a}} \\
\text { total }(\%)\end{array}$ & $\begin{array}{l}\text { Non } \\
\text { germinated } \\
\text { total }\end{array}$ & \\
\hline \multicolumn{5}{|c|}{ L1 35S::cTP-LOX } \\
\hline SL1/18 & 97 & $89(92)$ & 8 & $8 / 3$ \\
\hline SL1/32 & 92 & $50(54)$ & 42 & $8 / 1$ \\
\hline SL1/46B & 42 & $37(88)$ & 5 & $12 / 3$ \\
\hline SL1/47 & 96 & $71(74)$ & 25 & $7 / 2$ \\
\hline SL1/67 & 89 & $61(68)$ & 28 & $10 / 5$ \\
\hline SL1/138A & 64 & $51(79)$ & 13 & $5 / 1$ \\
\hline \multicolumn{5}{|c|}{ L3 35S::LOX } \\
\hline SL3/31A & 90 & $68(75)$ & 22 & $7 / 2$ \\
\hline SL3/41 & 92 & $32(35)$ & 60 & $7 / 2$ \\
\hline SL3/66A & 92 & $68(74)$ & 24 & $6 / 1$ \\
\hline SL3/70 & 96 & $78(81)$ & 18 & $7 / 0$ \\
\hline SL3/79A & 96 & $58(60)$ & 38 & $8 / 4$ \\
\hline SL3/155 & 96 & $75(78)$ & 21 & $6 / 4$ \\
\hline SL3/184A & 96 & $70(73)$ & 26 & $8 / 3$ \\
\hline SL3/187 & 96 & $71(74)$ & 25 & $5 / 3$ \\
\hline SL3/195 & 96 & $64(67)$ & 32 & $7 / 4$ \\
\hline SL3/238 & 98 & $60(61)$ & 38 & $7 / 4$ \\
\hline SL3/244 & 93 & $66(71)$ & 27 & $5 / 1$ \\
\hline SL3/252 & 96 & $85(88)$ & 11 & $6 / 3$ \\
\hline
\end{tabular}

plastidic 13-LOX in the wound-induced induction of proteinase inhibitors was demonstrated. The generated plants lacking this specific 13-LOX did not show a woundinduced JA formation (Royo et al., 1999).

Transgenic barley plants were generated by placing the full-length cDNA coding for LOX-100 and named $L O X 2: H v: 1$ (Vörös et al., 1998) from barley under the control of two different constitutive promoters: the CaMV $35 \mathrm{~S}$ promoter, known to be weak in cereals, and the monocotspecific maize polyubiquitin-1 (Ubi-1) promoter, shown to be highly active in monocots in transient (Schledzewski and Mendel, 1994) and stable transformation experiments ( $\mathrm{Li}$ et al., 1997). Furthermore, LOX-100-cDNA without the chloroplast targeting sequence driven by the $35 \mathrm{~S}$ promoter was included. Two identical promoters in the same construct may cause gene silencing (Matzke and Matzke, 1995; Kumpatla and Hall, 1998; Meng et al., 2003; Howarth et al., 2005). Therefore, vectors were designed containing either the $35 \mathrm{~S}$ promoter in front of LOX-100cDNA or the Ubi-1 promoter in front of the selectable gene or vice versa.

Twenty three independently transformed barley lines were produced using the L1 and 45 lines using the L3. The analyses of these plants revealed a transformation efficiency of $0.64 \%$ and $0.95 \%$, respectively, which is in accordance with other reports for cereal transformation (Rasco-Gaunt et al., 2001; Travella et al., 2005). Co-trans-

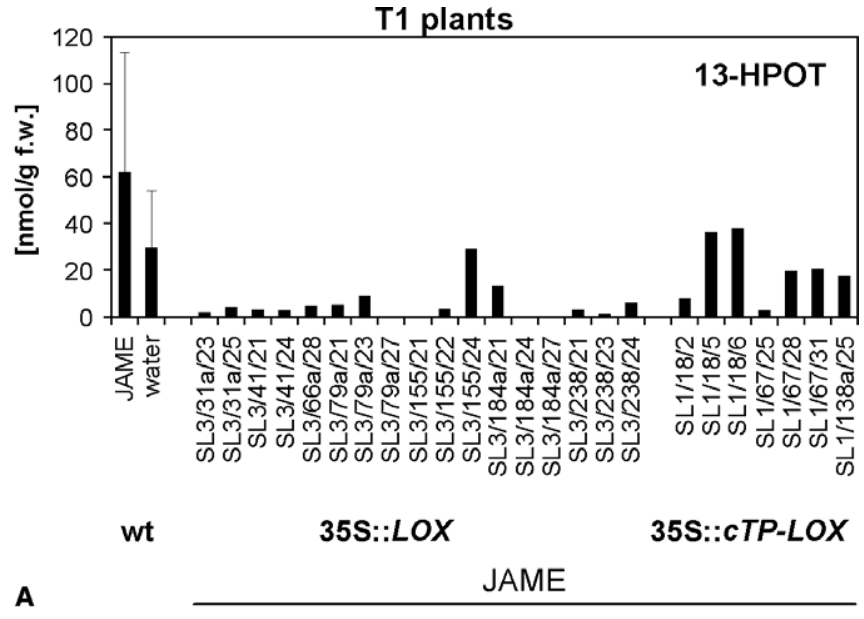

A
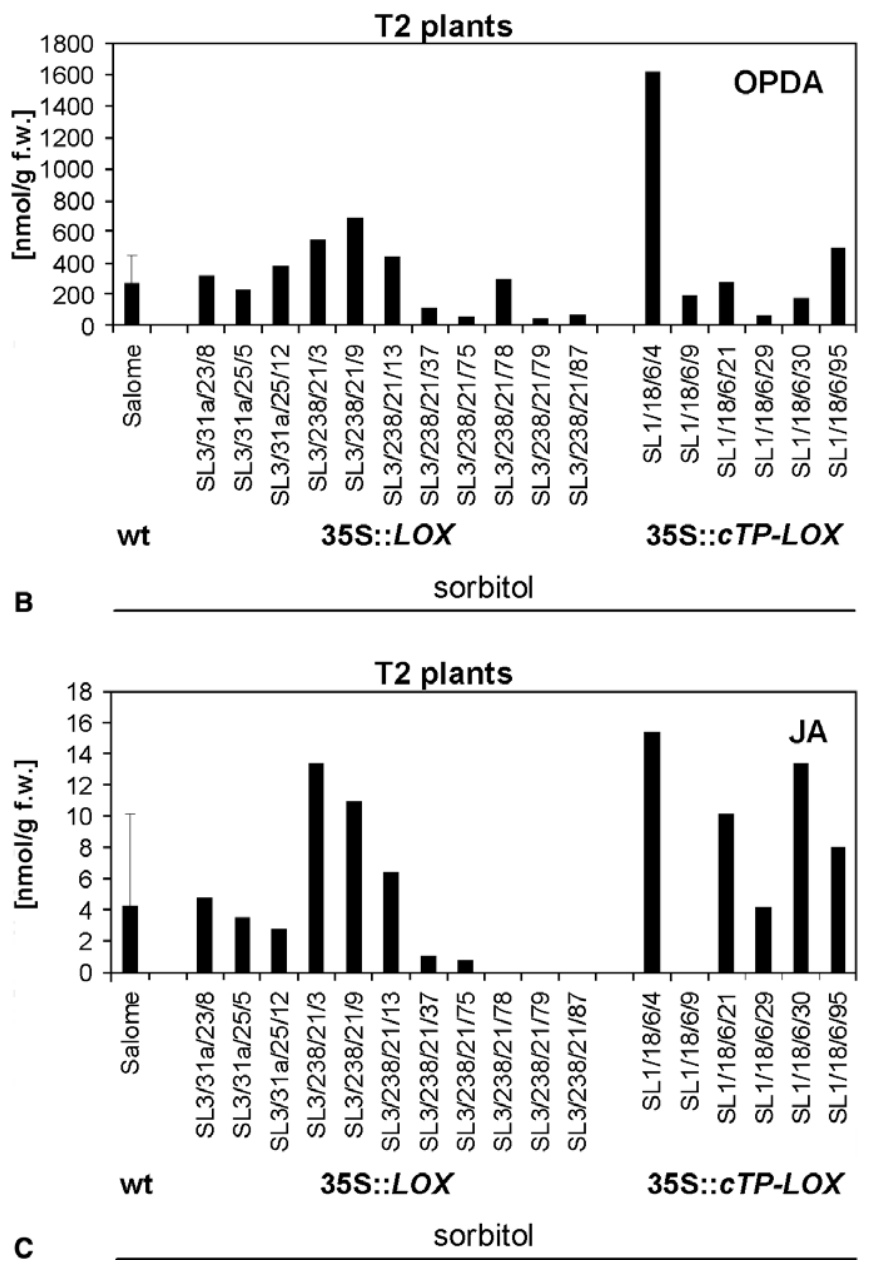

Fig. 5. Oxylipin analysis in transgenic barley plants. Leaf segments from well-developed and well-tillered greenhouse-grown $\mathrm{T} 1$ plants treated by flotation on $45 \mu \mathrm{M}$ JAME or on water for $36 \mathrm{~h}$ and from T2 plants, treated by flotation on $1 \mathrm{M}$ sorbitol for $24 \mathrm{~h}$, were used. Oxylipins were extracted and quantified as described under Section 4. 13-HPOT from T1 progeny (A), OPDA (B) and JA (C) from T2 plants. The controls show mean values of samples from twenty different wild type plants. Results from transgenic plants represent the results from one experiment.

formation efficiency for 35S::cTP-LOX and 35S::LOX was $26 \%$ and $31 \%$, respectively. These results correspond to the findings of many others as reviewed in Dahleen et al. 
(2001). The difference between the relatively high regeneration frequency on the selective agent in comparison to the transformation frequency is caused by (1) the remarkable loss of plants, which died after successful regeneration and by (2) escapes due to the PPT-based selective agent bialaphos. Approximately, 50\% of the selected plants were identified as escapes. These results are consistent with findings on a range of $30-80 \%$ escapes for cereal transformation (Nehra et al., 1994; Barro et al., 1998; Rasco-Gaunt et al., 2001).

The frequency of green plants selected on bialaphos was tenfold higher in lines transformed with LOX-100-cDNA driven by the $35 \mathrm{~S}$ promoter as compared to the Ubi-1 promoter. This might be due to different reasons. On the one hand, the strong Ubi-1 promoter may cause elevated levels of LOX-100 leading to problems in cell proliferation and regeneration. Such findings were reported for rice transformed with a fungal glucose oxidase gene, which leads to elevated levels of $\mathrm{H}_{2} \mathrm{O}_{2}$ and enhanced pathogen resistance. Comparing a constitutive (Ubi-1) with an inducible promoter, the number of transgenic plants was much lower, and plants carrying the Ubi promoter yielded lower viability and seed set (Kachroo et al., 2003). On the other hand, using the construct containing Ubi::cTP-LOX, the selectable gene is under the control of the $35 \mathrm{~S}$ promoter, which is less potent in cereals ( $\mathrm{Li}$ et al., 1997; Upadhyaya et al., 2000). This could cause insufficient expression of the selection marker leading to non-resistant plants under the selection pressure used. Moreover, the construct contains two promoters in the opposite orientation presumably resulting in RNA interference (Kooter et al., 1999) and integration sides of the foreign genes into the genome can lead to position effects.

Interestingly, a high percentage of the green and wellrooted plantlets, selected on a moderate level of bialaphos $(3 \mathrm{mg} / \mathrm{l})$, turned yellow and died despite selection pressure was already removed. To our knowledge, this was never reported before in cereal transformation and selection. The mortality frequency was the same for $35 \mathrm{~S}:: c T P-L O X$ and Ubi::cTP-LOX comprising both the LOX-100-cDNA with the chloroplast target sequence, whereas for $35 \mathrm{~S}:$ : $L O X$ a $15 \%$ lower percentage of dead plants was scored. Apart from the high percentage of plants died a negligible number of albinotic plantlets was observed. This phenomenon is described repeatedly in cereal tissue culture and also in transformation. In our study, frequency of the occurrence of albinos ranged from $4 \%$ to $7 \%$ which is rather low in comparison to others (Wan and Lemaux, 1994; Bregitzer and Campbell, 2001) and seems not to be related to overexpression of LOX-100-cDNA.

Constitutive occurrence of LOX-100 in the chloroplast seems to be detrimental for the plant as indicated by the mortality frequencies of plants expressing $L O X-100$ directed to the chloroplasts. This accords to the immunofluorescence data of the plantlets SL1/63 and SL2/9 which later died (Fig. 4C and D). A high amount of LOX-protein was detected in chloroplasts of the non-treated plant- lets. Accordingly, strong accumulation of LOX-100 and a dramatically altered ultrastructure of chloroplasts was found after treatment of wild type leaf segments with $45 \mu$ M JAME (Bachmann et al., 2002). A significant loss of well-structured thylakoid membranes and the number of stacks was observed after $24 \mathrm{~h}$ of treatment. It was concluded that JAME-induced lipid peroxidation of chloroplasts is an initial event preceding senescence. Our results using the transgenic approach provide further evidences for a link between LOX and senescence. Immunoblot analysis with leaves from yellow plants revealed a strong accumulation of LOX-98 indicating differential activity of LOXs during senescence. Recently, additional proofs were provided for Arabidopsis as well as barley demonstrating a role of JA in leaf senescence. Upon exogenous application of JA premature senescence in detached and attached leaves of Arabidopsis wild type plants was observed, whereas no changes were found in a JA-insensitive mutant (He et al., 2002). For barley, senescent associated genes with enhanced levels during leaf senescence under natural conditions like HvS40, a nucleus-targeted protein and the $h p d$ gene encoding 4-hydroxyphenylpyruvate dioxygenase, were also induced by JA (Krupinska et al., 2002; Falk et al., 2002).

Segregation analysis of T0 plants revealed that the transgene was stably transmitted to their progeny. In most of the lines, the transgene co-segregated with the bialaphos-resistant phenotype, confirming that the transgene behaved as a normal locus in the genome. T1 segregation, however, showed a Mendelian and nonMendelian segregation, probably due to gene silencing and multi copy integration. A high percentage of green seedlings of the progeny scored as bialaphos-resistant, did not grow vigorously after a certain period. It is tempting to speculate that overexpression of $L O X-100$ is the causative factor. Although LOX-100 might not to be involved in the germination and regeneration of plantlets via somatic embryogenesis, it seems that the overexpressed $L O X-100$ is active later during seedling development. This assumption is supported by the tissue-specific expression of allene oxide synthase (AOS), the first enzyme in the JA branch of the LOX-pathway. In six day old barley seedlings, AOS was clearly detectable in parenchymatic cells of the first internode where osmotic stress seems to occur (Maucher et al., 2000). The high abundance of LOX-100 in chloroplasts detected here may attribute a higher JA-level in such tissues leading to severe effects in plant growth and development. Indeed, plants overexpressing the LOX-100 directed into the plastids exhibited upon treatment of leaves with sorbitol higher levels of JA indicating that LOX-100 from barley is at least partially involved in synthesis of JA (Fig. 5C). In contrast, most of the lines carrying the LOX-100 in the cytoplasm exhibited lower levels of JA. Here, the levels of JA after sorbitol treatment exhibited high variations and did not seem to correlate to LOX100 protein levels. Since a LOX active in JA biosynthesis 
needs $\alpha$-LeA released from chloroplast membranes (Feussner and Wasternack, 2002), the LOX-100 if located in the cytosol may not function anymore in JA biosynthesis. It is unclear so far, whether the residual JA formation in $35 \mathrm{~S}:: L O X$ transgenic plants occurred due to another LOX form or the endogenous LOX100. In conclusion, our data obtained by stable transformation of barley with the LOX cDNA coding for a plastidic 13-LOX under control of a constitutive promotor revealed a role in plant development most likely due to an involvement in the regulation of senescence possibly by an increased level of the endogenous JA. The high number of plantlets which died after successful regeneration are in line with this assumption. Consequently, in further studies inducible promoters are an alternative to get deeper insights into the role of the LOX-100 in senescence.

\section{Experimental}

\subsection{Plasmid construction}

Three expression vectors were constructed that contain the LOX-100-cDNA from barley $(H$. vulgare L. cv. Salome) with or without chloroplast target sequence (Vörös et al., 1998) driven by different promoters (Fig. 1). The plasmids were constructed as follows:

Plasmid L1 (p35S::cTP-LOXUbi::bar). The vector contains the cDNA of LOX2:Hv:1 under control of the cauliflower mosaic virus $35 \mathrm{~S}$ promoter and the selectable bar gene (Thompson et al., 1987) driven by the maize polyubiquitin-1 (Ubi-1) promoter (Christensen et al., 1990). The LOX2:Hv:1 cDNA of $3053 \mathrm{bp}$ was inserted into pRT104 (Töpfer et al., 1988) using BamHI and XbaI restriction sites. The resulting 35S::lox::polyA fragment was inserted into pAHC20 vector (Christensen and Quail, 1996) using HindIII restriction sites.

Plasmid L2 (pUbi::cTP-LOX35S::pat). To create a vector containing the cDNA of $L O X 2: H v: 1$ under control of the Ubi- 1 promoter and the pat gene under control of the $35 \mathrm{~S}$ promoter, a basic vector construct containing a multiple cloning site (MCS) was prepared as described (Monostori et al., 2003). Full length LOX2:Hv:1 cDNA was inserted between the NotI and SpeI restriction sites of the MCS in sense orientation.

Plasmid L3 (p35S::LOXUbi::bar). A 109-bp fragment of the LOX-100-cDNA, containing non-coding sequences and the ATG start codon upstream the signal-peptide, was amplified by PCR using the $L O X 2: H v: 1$ cDNA and was inserted into pUC18 using the KpnI and SmaI restriction sites. A BamHI-PaeI fragment of a 'lox minus $\mathrm{CTP}^{\prime}$ construct cloned in pQE31 (Vörös et al., 1998) was ligated downstream to the 109-bp-fragment and cloned into pRT104 by replacing the full length $L O X 2: H v: 1$. Finally, the 35S::lox minus cTP::polyA fragment was inserted into pAHC20 as described above.

\subsection{Plant material, transformation and generation of transgenic plants}

The donor barley plants ( $H$. vulgare L. cv. Salome) were grown under environmentally controlled conditions in the greenhouse as described (Sharma et al., 2005). Caryopses were harvested and sterilized (Ryschka et al., 1991) and immature scutella were isolated as reported (Hänsch et al., 1996). Transformation was performed with all three constructs using the BIOLISTIC ${ }^{\mathrm{TM}}$ particle delivery system according to the procedure described earlier (Koprek et al., 1996). Transformed scutella were selected on MS-based medium (Murashige and Skoog, 1962) containing $3 \mathrm{mg} / \mathrm{l}$ bialaphos (Duchefa, Haarlem, The Netherlands) and putative transgenic plants were generated as described recently (Sharma et al., 2005). A continuous supply of material enabled two independent transformation experiments per month each including 250-350 scutella.

\subsection{Analysis of expression of the selectable gene}

Mesophyll protoplasts as well as samples of bialaphosresistant calli and regenerated plantlets were tested for the presence of PAT as described by De Block et al. (1987). For a large screening of bialaphos-resistant T0 plants, the PPT leaf painting assay was performed using $3-5 \mathrm{~cm}$ segments of leaf tips before spikes emerged. Four to six segments per plant were placed between two filter papers wetted with $0.25 \%(\mathrm{w} / \mathrm{v})$ glufosinate ammonium (Duchefa) in a Petri dish and kept under light at $4{ }^{\circ} \mathrm{C}$ for 2 weeks. To detect functional expression of the bar gene in T1 progeny, a bialaphos-resistance test was performed. Seeds of selfed T0 plants were sterilized as described (Müller et al., 1989), mature embryos were excised and cultured on hormone-free MS medium containing $5 \mathrm{mg} / \mathrm{l}$ bialaphos. After 2 weeks, bialaphos-resistant well germinated seedlings were counted and selected as $\mathrm{T} 1$ progeny which were transferred to soil.

\subsection{Molecular identification of transgenic plants}

Total genomic DNA was isolated by homogenising $1 \mathrm{~g}$ of frozen leaf tissue of primary transformants (T0) and their selected progeny (T1 and T2) according to Kleinhofs and Kudrna (1991). The presence of the selectable pat gene was determined by PCR using the oligonucleotide primers pat 5 (5'-CAA TCA CTA CAT CGA GAC GAG C-3') and pat $3\left(5^{\prime}\right.$-AAG TCG CGC TGC CAG AAC-3') resulting in a 429-bp fragment. For determination of bar, the primer set bar 5 (5'-GGT CTG CAC CAT CGT CAA CCA CTA CAT- $\left.3^{\prime}\right)$ and bar 3 (5'-GCA GGC TGA AGT CCA GCT GCC AGA AAC-3') was chosen amplifying a 452-bp PCR product.

To test the presence of the cDNA of LOX-100, two primer sets were used: (i) primer HvLOX-100int a (5'TGC TCC ACC TCT TCA AGC TC-3') and primer 
HvLOX-100int b (5'-AGC AAC AGG TCG TGG TAG TC-3') resulting in two PCR fragments: 675 bp (exo$\mathrm{n}+$ intron) from the endogenous gene and $335 \mathrm{bp}$ (exon) from the transgene; and (ii) primer $35 \mathrm{~S}$-promoter region 351-368: (5'-TCT CCA CTG ACG TAA GGG-3') (pRT CORE+; Benfey et al., 1989) and primer HvLOX-100int $\mathrm{b}$ resulting in an amplification product of $1600 \mathrm{bp}$ which represents $35 \mathrm{~S}$ promoter segment linked to LOX-100cDNA. The cloned PCR-fragment was sequenced with the ABI Prism Big Dye Terminator Cycle Sequencing Ready Reaction Kit on an ABI Prism 310 cycle sequencer (PE Applied Biosystems, Warrington, UK) with a pop 6 polymer.

PCR analysis was carried out using $200 \mathrm{ng}$ genomic DNA of putative transgenic plants and non-transformed plants (serving as a negative control), and $10 \mathrm{ng}$ plasmid DNA (serving as a positive control) using Taq DNA polymerase and corresponding buffers from PeqLab (Biotechnologie $\mathrm{GmbH}$, Erlangen, Germany) according to manufacturer's instructions. The basic thermocycling conditions for the detection of different genes consisted: 5 min initial denaturation at $94{ }^{\circ} \mathrm{C}$ one cycle followed by 36 cycles of $30 \mathrm{~s}$ denaturation at $94{ }^{\circ} \mathrm{C}, 30 \mathrm{~s}$ annealing at $59^{\circ} \mathrm{C}, 1 \mathrm{~min}$ extension at $72{ }^{\circ} \mathrm{C}$ for the bar and lox while $2.5 \mathrm{~min}$ extension at $72{ }^{\circ} \mathrm{C}$ each cycle for the $35 \mathrm{~S}$ promoter region, and the reaction was ended with a 10-min final extension step at $72{ }^{\circ} \mathrm{C}$, cooled and kept at $4{ }^{\circ} \mathrm{C}$ in a HYBAID PCR Express Thermal Cycler (UK). PCR amplification products were separated by agarose gel electrophoresis $(1.2 \%, \mathrm{w} / \mathrm{v})$, visualized with ethidium bromide staining, and photographed under UV light.

\subsection{Immunoblot analysis}

Total proteins from protoplasts, leaves of bar and pat positive $\mathrm{T} 0$ and $\mathrm{T} 1$ plants as well as from leaf segments of wild type plants floated either on $45 \mu \mathrm{M}$ JAME (Firmenich, Geneva, Switzerland) or on water for $36 \mathrm{~h}$, were extracted according to Meyer et al. (1988), solubilized in SDS sample buffer and subjected to SDS-PAGE. Immunoblot analyses were performed as described by Feussner et al. (1995).

\subsection{Immunofluorescence microscopy}

Leaf segments (ca. $10 \mathrm{~mm}^{2}$ in size) from regenerated wild type and $\mathrm{T} 0$ plants growing in vitro were fixed, dehydrated and embedded in PEG as described (Feussner et al., 1995). Immunolabelling of $2 \mu \mathrm{m}$ thick sections was done with anti-LB LOX I (dilution 1:500) as primary antibody and goat anti-rabbit-IgG conjugated with AlexaFluor488 (Molecular Probes, Leiden, The Netherlands) as secondary antibody. DAPI-staining and visualization of the immunolabelled LOX-100 were done as described (Feussner et al., 1995). Control experiments were performed by using the pre-immune serum.

\subsection{Measurement of $L O X$ products}

Leaf material was used from well-developed T0 plants as well as from corresponding wild type plants grown in the greenhouse. For analysis of T1 plants selected in vitro via the germination assay, leaf material was harvested from well-developed plants again six weeks after transfer into soil. These leaf segments were harvested fresh (non-treated) as well as treated by floating on $45 \mu \mathrm{M}$ JAME for $36 \mathrm{~h}$. Additionally, leaf segments from 20 corresponding wild type plants were used in the same manner. For analysis of T2 plants, $3-5 \mathrm{~cm}$ segments of the primary leaf from 7 days old seedlings originating from seeds of lox positive T1 plants and from 25 wild type seedlings were used and treated by flotation on $1 \mathrm{M}$ sorbitol for $24 \mathrm{~h}$. In all cases treatment was carried out at $24 \pm 1{ }^{\circ} \mathrm{C}$ and continuous white light set at $130 \mu \mathrm{mol} \mathrm{m}^{-2} \mathrm{~s}^{-1}$.

LOX-derived products were analysed as described before, but with some modifications (Göbel et al., 2003; Weichert et al., 2002). Frozen plant material was added to $20 \mathrm{ml}$ of extraction medium (hexane:2-propanol, 3:2 $(\mathrm{v} / \mathrm{v})$, with $0.0025 \%(\mathrm{w} / \mathrm{v})$ butylated hydroxytoluene) and was immediately homogenized with an Ultra Turrax for $45 \mathrm{~s}$ under a stream of argon on ice. The extract was shaken for $10 \mathrm{~min}$ and centrifuged at $3200 \mathrm{~g}$ at $4{ }^{\circ} \mathrm{C}$ for $15 \mathrm{~min}$. The clear upper phase was collected, and a $6.7 \%(\mathrm{w} / \mathrm{v})$ solution of potassium sulfate was added up to a volume of $32.5 \mathrm{ml}$. After vigorous shaking and centrifugation at $3200 \mathrm{~g}$ at $4{ }^{\circ} \mathrm{C}$ for $10 \mathrm{~min}$, the upper hexane-rich layer which potentially contained oxylipins was subsequently dried under a nitrogen stream. The remaining lipids were re-dissolved in $0.2 \mathrm{ml}$ of methanol and stored under an argon atmosphere at $-20^{\circ} \mathrm{C}$ until use.

Subsequently, esterified fatty acids were transmethylated with sodium methoxide and free fatty acids were methylated with EDAC (Op den Camp et al., 2003). The analysis of the corresponding fatty acid methyl esters was performed with an Agilent (Waldbronn, Germany) 6890 gas chromatograph fitted with a capillary DB-23 column $(30 \mathrm{~m} \times 0.25 \mathrm{~mm} ; 0.25 \mu \mathrm{m}$ coating thickness; J\&W Scientific, Agilent). Helium was used as carrier gas $(1 \mathrm{ml} / \mathrm{min})$. The temperature gradient was $150{ }^{\circ} \mathrm{C}$ for $1 \mathrm{~min}, 150-200{ }^{\circ} \mathrm{C}$ at $8 \mathrm{~K} / \mathrm{min}, 200-250{ }^{\circ} \mathrm{C}$ at $25 \mathrm{~K} / \mathrm{min}$ and $250{ }^{\circ} \mathrm{C}$ for $6 \mathrm{~min}$. As internal standard for the quantification of esterified fatty acids, triheptadecanoate was used. As internal standard for the quantification of free fatty acids, heptadecanoic acid was used. For the determination the position of double bound positions in fatty acids not present in the standard mixture (16:1 (n-5), 20:1 (n-9), 20:3 (n-6) 20:4 (n-6) and 20:5 $(n-3))$, fatty acid methyl esters were converted into their 4,4-dimethyloxazoline derivatives as described (Sperling et al., 2000) and analysed mass-spectrometrically according to Christie (1998), using the 6890 Gas Chromatograph/5973 Mass Selective Detector system (Agilent). 
For analysis of free oxylipins, samples were directly subjected to HPLC analysis. First, oxylipins were purified by reverse-phase HPLC. This was performed on an ET250/2 Nucleosil $120-5$ C18 column $(250 \times 2.1 \mathrm{~mm}, 5 \mu \mathrm{m}$ particle size; Macherey \& Nagel, Düren, Germany) with a methanol:water:acetic acid $(85: 15: 0.1, \mathrm{v} / \mathrm{v} / \mathrm{v})$ solvent system at a flow rate of $0.18 \mathrm{ml} / \mathrm{min}$. Straight-phase HPLC for separation of hydroperoxy fatty acids, hydroxy fatty acids as well as keto fatty acids was performed on a Zorbax Rx-SIL column $(150 \times 2.1 \mathrm{~mm}, 5 \mu \mathrm{m}$ particle size, Agilent $)$ with $n$-hexane:2-propanol:acetic acid $(100: 1: 0.1, \mathrm{v} / \mathrm{v} / \mathrm{v})$ as a solvent system at a flow rate of $0.2 \mathrm{ml} / \mathrm{min}$. For detection of the hydroperoxy fatty acids and hydroxy fatty acids, the absorbance at $234 \mathrm{~nm}$ indicating the conjugated diene system was recorded. For detection of keto fatty acids, absorbance at $270 \mathrm{~nm}$ was recorded. The enantiomer composition of the hydroperoxy fatty acids as well as hydroxy fatty acids was analysed by chiral-phase HPLC on a Chiral OD-H column $(150 \times 2.1 \mathrm{~mm}, 5 \mu \mathrm{m}$ particle size; Baker, Griesheim, Germany) with $n$-hexane:2-propanol:acetic acid $(100: 5: 0.1, \mathrm{v} / \mathrm{v} / \mathrm{v})$ as a solvent system at a flow rate of $0.1 \mathrm{ml} / \mathrm{min}$. For quantification of these oxylipins, $(6 Z, 9 Z, 11 E, 13 S)$-13-hydroxy-6,9,11-octadecatrienoic acid was used as the internal standard. For detection of JA, OPDA, and dinor-OPDA, these compounds were converted to their pentafluorobenzyl esters after purification by RP-HPLC according to Müller and Brodschelm (1994). The analysis was carried out using a ThermoFinnigan (Austin, Texas, USA) Polaris Q mass selective detector connected to ThermoFinnigan Trace gas chromatograph equipped with a capillary Rtx-5MS column $(15 \mathrm{~m} \times 0.25 \mathrm{~mm}, 0.25 \mu \mathrm{m}$ coating thickness; Resteck, Bad Homburg, Germany). Helium was used as carrier gas $(1 \mathrm{ml} / \mathrm{min})$. The temperature gradient was $60^{\circ} \mathrm{C}$ for $1 \mathrm{~min}, 60-180^{\circ} \mathrm{C}$ at $25 \mathrm{~K} / \mathrm{min}, 180-270^{\circ} \mathrm{C}$ at $5 \mathrm{~K} / \mathrm{min}$, $270{ }^{\circ} \mathrm{C}$ for $1 \mathrm{~min}, 270-300{ }^{\circ} \mathrm{C}$ at $10 \mathrm{~K} / \mathrm{min}, 300^{\circ} \mathrm{C}$ for $20 \mathrm{~min}$. The pentafluorobenzyl esters were detected by negative chemical ionisation with ammonium as ionisation gas. Under these conditions, the retention times of the pentafluorobenzyl esters of JA, OPDA, and dinor-OPDA were $11.7,20.9$, and $18.1 \mathrm{~min}$, respectively. For quantification,

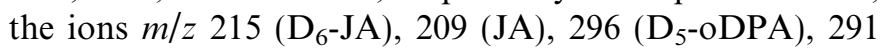
(OPDA), and 263 (dinor-OPDA) were used, respectively.

Aldehydes were extracted and analysed as described (Kohlmann et al., 1999).

\section{Acknowledgements}

This work was supported by a Grant through the "Forschungsschwerpunkt Agrarbiotechnologie des Landes Niedersachsen". We are grateful to Christian Böhme, Sabine Freitag, Pia Meyer and Christin Klockmann for excellent technical assistance. We also thank Helmut Maucher for his help in preparation of the LOX constructs.

\section{References}

Bachmann, A., Hause, B., Maucher, H., Garbe, E., Vörös, K., Weichert, H., Wasternack, C., Feussner, I., 2002. Jasmonate-induced lipid peroxidation in barley leaves initiated by distinct 13-LOX forms of chloroplasts. Biol. Chem. 383, 1645-1657.

Barro, F., Cannell, M.E., Lazzeri, P.A., Barcelo, P., 1998. The influence of auxins on transformation of wheat and tritordeum and analysis of transgene integration patterns in transformants. Theor. Appl. Genet. 97, 684-695.

Bate, N.J., Rothstein, S.J., 1998. C6-volatiles derived from the lipoxygenase pathway induce a subset of defense-related genes. Plant J. 16, 561-569.

Bell, E., Creelman, R.A., Mullet, J.E., 1995. A chloroplast lipoxygenase is required for wound induced jasmonic acid accumulation in Arabidopsis. Proc. Natl. Acad. Sci. USA 92, 8675-8679.

Benfey, P., Ren, L., Chua, N., 1989. The CaMV 35S enhancer contains at least two domains which can confer different developmental and tissuespecific expression patterns. EMBO J. 8, 2195-2202.

Bregitzer, P., Campbell, R.D., 2001. Genetic markers associated with green and albino plant regeneration from embryogenic barley callus. Crop Sci. 41, 173-179.

Christensen, A.H., Quail, P.H., 1996. Ubiquitin promoter-based vectors for high-level expression of selectable and/or screenable marker genes in monocotyledonous plants. Transgenic Res. 5, 213-218.

Christensen, A.H., Sharrock, R.A., Quail, P.H., 1990. Maize polyubiquitin genes: structure, thermal perturbation of expression and transcript splicing, and promoter activity following transfer to protoplasts by electroporation. Plant Mol. Biol. 18, 675-689.

Christie, W.W., 1998. Gas chromatography-mass spectrometry methods for structural analysis of fatty acids. Lipids 33, 343-353.

Croft, K.P.C., Jüttner, F., Slusarenko, A.J., 1993. Volatile products of the lipoxygenase pathway evolved from Phaseolus vulgaris (L.) leaves inoculated with Pseudomonas syringae pv. phaseolica. Plant Physiol. 101, 13-24.

Dahleen, L.S., Okubara, P.A., Blechl, A.E., 2001. Transgenic approaches to combat Fusarium Head Blight in wheat and barley. Crop Sci. 41, 628-637.

De Block, M., Botterman, J., Vandewiele, M., Dockx, J., Thoen, C., Gosselé, V., Movva, N.R., Thompson, C., van Montagu, M., Leemans, J., 1987. Engineering herbicide resistance in plants by expression of a detoxifying enzyme. EMBO J. 6, 2513-2518.

Devoto, A., Turner, J.G., 2005. Jasmonate-regulated Arabidopsis stress signalling network. Physiol. Plant. 123, 161-172.

Falk, J., Krauß, N., Dähnhardt, D., Krupinska, K., 2002. The senescence associated gene of barley encoding 4-hydroxyphenylpyruvate dioxygenase is expressed during oxidative stress. J. Plant Physiol. 159, 12451253.

Feussner, I., Wasternack, C., 2002. The lipoxygenase pathway. Annu. Rev. Plant Biol. 53, 275-297.

Feussner, I., Hause, B., Vörös, K., Parthier, B., Wasternack, C., 1995. Jasmonate-induced lipoxygenase forms are localized in chloroplasts of barley leaves (Hordeum vulgare cv. Salome). Plant J. 7, 949-957.

Göbel, C., Feussner, I., Rosahl, S., 2003. Lipid peroxidation during the hypersensitive response in potato in the absence of 9-lipoxygenases. J. Biol. Chem. 278, 52834-52840.

Hänsch, R., Koprek, T., Heydemann, H., Mendel, R.R., Schulze, J., 1996. Electroporation-mediated transient gene expression in isolated scutella of Hordeum vulgare. Physiol. Plant. 98, 20-27.

Hause, B., Vörös, K., Kogel, K.H., Bessercand, K., Wasternack, C., 1999. A jasmonate-responsive lipoxygenase of barley leaves is induced by plant activators but not by pathogens. J. Plant Physiol. 154, 459-462.

He, Y., Fukushige, H., Hildebrand, D.F., Gan, S., 2002. Evidence supporting a role of jasmonic acid in Arabidopsis leaf senescence. Plant Physiol. 128, 876-884.

Howarth, J.R., Jacquet, J.N., Doherty, A., Jones, H.D., Cannell, M.E., 2005. Molecular genetic analysis of silencing in two lines of Triticum 
aestivum transformed with the reporter gene construct pAHC25. Annals Appl. Biol. 146, 311-320.

Howe, G.A., 2004. Jasmonates as signals in the wound response. J. Plant Growth Regul. 23, 223-237.

Kachroo, A., He, Z., Patkar, R., Zhu, Q., Zhong, J., Li, D., Ronald, P., Lamb, C., Chattoo, B.B., 2003. Induction of $\mathrm{H}_{2} \mathrm{O}_{2}$ in transgenic rice leads to cell death and enhanced resistance to both bacterial and fungal pathogens. Transgenic Res. 12, 577-586.

Kleinhofs, A., Kudrna, D., 1991. Isolation of plant genomic DNA Laboratory Protocoll. Washington State University, Department of Genetics, Pullman, USA.

Koch, T., Krumm, T., Jung, V., Engelberth, J., Boland, W., 1999. Differential induction of plant volatile biosynthesis in the lima bean by early and late intermediates of the octadecanoid-signaling pathway. Plant Physiol. 121, 153-162.

Kohlmann, M., Bachmann, A., Weichert, H., Kolbe, A., Balkenhohl, T., Wasternack, C., Feussner, I., 1999. Formation of lipoxygenasepathway derived aldehydes in barley leaves upon methyl jasmonate treatment. Eur. J. Biochem. 260, 885-895.

Kooter, J.M., Matzke, M.A., Meyer, P., 1999. Listening to the silent genes: transgene silencing, gene regulation and pathogen control. Trends Plant Sci. 4, 340-347.

Koprek, T., Hänsch, R., Nerlich, A., Mendel, R.R., Schulze, J., 1996. Fertile transgenic barley of different cultivars obtained by adjustment of bombardment conditions to tissue response. Plant Sci. 119, 79-91.

Krupinska, K., Haussühl, K., Schäfer, A., Van der Kooij, T.A.W., Leckband, G., Lörz, H., Falk, J., 2002. A novel nucleus-targeted protein is expressed in barley leaves during senescence and pathogen infection. Plant Physiol. 130, 1172-1180.

Kumpatla, S.P., Hall, T.C., 1998. Recurrent onset of epigenetic silencing in rice harboring a multi-copy transgene. Plant J. 14, 129-135.

Lehmann, J., Atzorn, R., Brückner, C., Reinbothe, S., Leopold, J., Wasternack, C., Parthier, B., 1995. Accumulation of jasmonate, abscisic acid, specific transcripts and proteins in osmotically stressed barley leaf segments. Planta 197, 156-162.

Li, Z., Upadhyaya, N.M., Meena, S., Gibbs, A.J., Waterhouse, P.M., 1997. Comparison of promoters and selectable marker genes for use in Indica rice transformation. Mol. Breed. 3, 1-14.

Matzke, M., Matzke, A.J.M., 1995. How and why do plants inactivate homologous (Trans)genes? Plant Physiol. 107, 679-685.

Maucher, H., Hause, B., Feussner, I., Ziegler, J., Wasternack, C., 2000. Allene oxide synthases of barley (Hordeum vulgare cv. Salome): tissue specific regulation in seedling development. Plant J. 21, 199-213.

Mène-Saffrané, L., Esquerré-Tugayé, M.-T., Fournier, J., 2003. Constitutive expression of an inducible lipoxygenase in transgenic tobacco decrease susceptibility tp Phytophthora parasitica var. nicotianae. Mol. Breed. 12, 271-282.

Meng, L., Bregitzer, P., Zhang, S., Lemaux, P.G., 2003. Methylation of the exon/intron region in the Ubil promoter complex correlates with transgene silencing in barley. Plant Mol. Biol. 53, 327-340.

Meyer, L., Grosset, J., Chartier, Y., Cleyet-Marel, J.-C., 1988. Preparation by two-dimensional electrophoresis of proteins for antibody production: antibody against proteins whose synthesis is reduced by auxin in tobacco mesophyll protoplasts. Electrophoresis 9, 704-712.

Monostori, T., Schulze, J., Sharma, V.K., Maucher, H., Wasternack, C., Hause, B., 2003. Novel plasmid vectors for homologous transformation of barley (Hordeum vulgare L.) with JIP23 cDNA in sense and antisense orientation. Cereal Res. Commun. 31, 17-24.

Müller, M.J., Brodschelm, W., 1994. Quantification of jasmonic acid by capillary gas chromatography-negative chemical ionization-mass spectrometry. Anal. Biochem. 218, 425-435.

Müller, B., Schulze, J., Wegner, U., 1989. Establishment of barley cell suspension cultures of mesocotyl origin suitable for isolation of dividing protoplasts. Biochem. Physiol. Pflanzen 185, 123-130.

Murashige, T., Skoog, F., 1962. A revised medium for rapid growth and bioassays with tobacco tissue cultures. Physiol. Plant. 15, 473-497.

Nehra, N.S., Chibbar, R.N., Leung, N., Caswell, K., Mallard, C., Steinhauer, L., Baga, M., Kartha, K.K., 1994. Self-fertile transgenic wheat plants regenerated from isolated scutellar tissues following microprojectile bombardment with two distinct gene constructs. Plant J. 5, 285-297.

Op den Camp, R.G.L., Przybyla, D., Ochsenbein, C., Laloi, C., Kim, C., Danon, A., Wagner, D., Hideg, E., Göbel, C., Feussner, I., Nater, M., Apel, K., 2003. Rapid induction of distinct stress responses after the release of singlet oxygen in Arabidopsis. Plant Cell 15, 23202332.

Paré, P.W., Tumlinson, J.H., 1997. De novo biosynthesis of volatiles induced by insect herbivory in cotton plants. Plant Physiol. 114, 11611167.

Pozo, M.J., Van Loon, L.C., Pieterse, C.M.J., 2004. Jasmonates signals in plant-microbe interactions. J. Plant Growth Regul. 23, 211-222.

Rancé, I., Fournier, J., Esquerré-Tugayé, M.-T., 1998. The incompatible interaction between Phytophthora parasitica var. nicotianae race 0 and tobacco is suppressed in transgenic plants expressing antisense lipoxygenase sequences. Proc. Natl. Acad. Sci. USA 95, $6554-6559$.

Rasco-Gaunt, S., Riley, A., Cannell, M., Barcelo, P., Lazzeri, P.A., 2001. Procedures allowing the transformation of a range of European elite wheat (Triticum aestivum L.) varieties via particle bombardment. J. Exp. Bot. 52, 865-874.

Rosahl, S., 1996. Lipoxygenases in plants - their role in development and stress response. Z. Naturforsch. 51c, 123-138.

Royo, J., Leon, J., Vancanneyt, G., Albar, J.P., Rosahl, S., Ortego, F., Castanera, P., Sanchez-Serrano, J.J., 1999. Antisense mediated depletion of a potato lipoxygenase reduces wound induction of proteinase inhibitors and increase weight gain of insect pests. Proc. Natl. Acad. Sci. USA 96, 1146-1151.

Ryschka, S., Ryschka, U., Schulze, J., 1991. Anatomical studies on the development of somatic embryoids in wheat and barley explants. Biochem. Physiol. Pflanzen 187, 31-41.

Schledzewski, K., Mendel, R.R., 1994. Quantitative transient gene expression: comparison of the promoters for maize polyubiquitin1, rice actin 1, maize-derived Emu and CaMV $35 \mathrm{~S}$ in cells of barley, maize and tobacco. Transgenic Res. 3, 249-255.

Sharma, V.K., Hänsch, R., Mendel, R.R., Schulze, J., 2005. Seasonal effect on tissue culture response and plant regeneration frequency from non-bombarded and bombarded immature scutella of barley (Hordeum vulgare L.) harvested from controlled environment. Plant Cell Tiss. Org. Cult. 81, 19-26.

Sperling, P., Blume, A., Zahringer, U., Heinz, E., 2000. Further characterization of Delta(8)-sphingolipid desaturases from higher plants. Biochem. Soc. Trans. 28, 638-641.

Thompson, C.J., Movva, N.R., Tizard, R., Crameri, R., Davies, J.E., Lauwereys, M., Botterman, J., 1987. Characterization of the herbicideresistance gene bar from Streptomyces hygroscopicus. EMBO J. 6, 2519-2523.

Töpfer, R., Schell, J., Steinbiss, H.H., 1988. Versatile cloning vectors for gene expression and direct gene transfer in plant cells. Nucleic Acids Res. 16, 8725 .

Travella, S., Ross, M., Harden, J., Everett, C., Snape, J.W., Harwood, W.A., 2005. A comparison of transgenic barley lines produced by particle bombardment and Agrobacterium-mediated techniques. Plant Cell Rep. 23, 780-789.

Upadhyaya, N.M., Surin, B., Ramm, K., Gaudron, J., Schünmann, Petra H.D., Taylor, W., Waterhouse, P.M., Wang, M.-B., 2000. Agrobacterium-mediated transformation of Australian rice cultivars Jarrah and Amaroo using modified promoters and selectable markers. Aust. J. Plant Physiol. 27, 201-210.

Vörös, K., Feussner, I., Kühn, H., Lee, J., Graner, A., Löbler, M., Parthier, B., Wasternack, C., 1998. Characterization of a methyljasmonate-inducible lipoxygenase from barley (Hordeum vulgare cv. Salome) leaves. FEBS Eur. J. Biochem. 251, 36-44.

Wan, Y., Lemaux, P.G., 1994. Generation of large numbers of independently transformed fertile barley plants. Plant Physiol. 104, $37-48$. 
Wasternack, C., Hause, B., 2002. Jasmonates and octadecanoids - signals in plant stress responses and development. Progr. Nucleic Acids Res. $72,165-220$.

Weber, H., 2002. Fatty acid derived signals in plants. Trends in Plant Sci. 7, 217-224.

Weber, H., Chételat, A., Caldelari, D., Farmer, E.E., 1999. Divinyl ether fatty acid synthesis in late blight-diseased potato leaves. Plant Cell 11, 485-493.
Weichert, H., Stenzel, I., Berndt, E., Wasternack, C., Feussner, I., 1999. Metabolic profiling of oxylipins upon salicylate treatment in barley leaves - preferential induction of the reductase pathway by salicylate. FEBS Lett. 464, 133-137.

Weichert, H., Kolbe, A., Kraus, A., Wasternack, C., Feussner, I., 2002. Metabolic profiling of oxylipins in germinating cucumber seedlings lipoxygenase-dependent degradation of triacylglycerols and biosynthesis of volatile aldehydes. Planta 215, 612-619. 